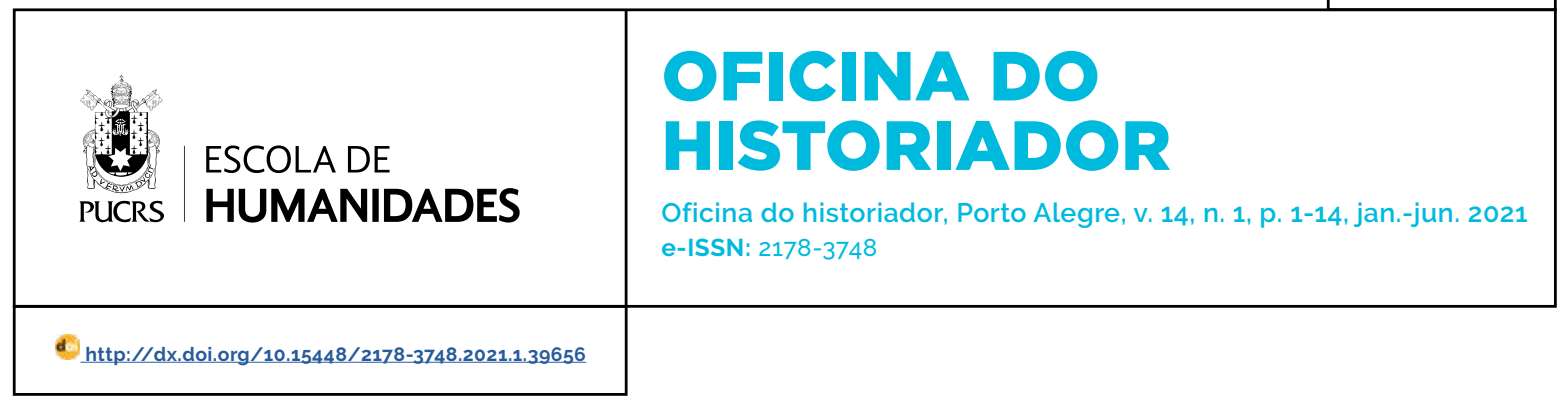

SEÇÃO: DOSSIÊ

\title{
A legitimação de Costa e Silva nas páginas da revista Realidade (1966-1967)
}

The legitimation of Costa e Silva at the pages of the "Realidade" magazine (1966-1967)

\author{
Jonas Migotto Filho ${ }^{1}$ \\ orcid.org/0000-0001-9325-6336 \\ migottojonas@gmail.com
}

Recebido em: 29/11/2020

Aprovado em: 08/12/2020.

Publicado em: 29/07/2021.
Resumo: Este artigo tem como objetivo analisar o perfil "Feliz Aniversário Seu Artur", publicado na revista Realidade de maio de 1966. A reportagem sobre Artur da Costa e Silva, ministro da Guerra na época de publicação, prenuncia sua chegada ao cargo de lider do governo ditatorial no Brasil. Realidade era uma revista considerada transgressora quando abordava o plano dos costumes, entretanto, mantinha diálogo com setores conservadores, como nos perfis dos ditadores, constantemente publicados durante os primeiros anos do periódico, sempre escritos por Luiz Fernando Mercadante. Dessa forma, pretende-se compreender, por meio de uma análise crítica da narrativa, as estratégias utilizadas para construir o personagem, que foi retratado, posteriormente, em mais três oportunidades, direta ou indiretamente, evidenciando uma negociação simbólica entre a revista e a Ditadura Civil-Militar. Por isso, busca-se, também, compreender os modos de operação da ideologia na versão final que chegava aos leitores. Além disso, discute-se a possibilidade de utilização das revistas não só como fontes, mas como objetos em si na pesquisa histórica, capazes de desvelar os jogos de poder de uma época. Por fim, percebe-se que o perfil evidencia as relações de poder entre a Realidade e a Ditadura, pelas escolhas presentes no texto e pelo cuidado em reconstruir Costa e Silva em outras ocasiões, legitimando o perfilado ao público leitor.

Palavras-chave: Revista Realidade. Ditadura Civil-Militar. Artur da Costa e Silva

Abstract: This article aims to analyze the profile "Feliz Aniversário Seu Artur", published in the Realidade magazine May 1966. The article about the Minister of War, Artur da Costa e Silva, antecipates his arrival as leader of dictatorial government in Brazil. Realidade was a magazine considered transgressive when it approached the plan of customs, however, it maintained dialogue with conservative sectors, as in the profiles of dictators constantly published during the first years of the magazine, always written by Luiz Fernando Mercadante. Thus, it is intended to understand, through a critical analysis of the narrative, the strategies used to build the character, which would be introduced in three more opportunities, directly or indirectly, showing a symbolic negotiation between the magazine and the Civil-Military Dictatorship. For this reason, it also seeks to understand the ideology's modes of operation in the final version. In addition, it discusses the possibility of using magazines not only as sources, but as objects in historical research, capable of revealing the relations of power. Finally, it is perceived that the profile evidences the power relations between Realidade and Dictatorship, by the choices present in the text and by the care in reconstructing Costa e Silva in other occasions, legitimating him to the reading public.

Keywords: Realidade magazine, Civil-Military Dictatorship. Artur da Costa e Silva. 


\section{Introdução}

A revista Realidade, publicada pela editora Abril entre os anos de 1966 e 1976, durante o período da Ditadura Civil-Militar no Brasil, é uma valorosa fonte para estudos. A publicação, especialmente nos seus primeiros anos (1966-1968), período conhecido como a primeira fase da revista, ${ }^{2}$ traz uma diversidade de pautas com textos cuidadosos, geralmente em estilo jornalismo literário, e aprofundamento em questões consideradas transgressoras para os valores morais do periodo. Tanto é que, quando abordou temas como "A juventude diante do sexo" ou "A mulher brasileira, hoje"3, sofreu censura, com a justificativa de que os conteúdos eram "obscenos".4 Entretanto, embora predominante, o caráter transgressor (FARO, 1999) não era único durante essa primeira fase. O conservadorismo também se fazia presente em suas páginas, principalmente, ao perfilar os militares que estavam no poder, como Humberto de Alencar Castelo Branco, Artur da Costa e Silva e Emilio Garrastazu Médici. Todos esses perfis foram escritos pelo repórter Luiz Fernando Mercadante, em uma espécie de elo entre a revista e os setores conservadores. Seu bom trânsito com a direita possibilitou encontros com os ditadores para traçar textos elogiosos e edificantes de suas figuras, legitimando-as para o público leitor. Mas essa legitimação pode ser vista como uma via de mão dupla, como afirmam alguns ex-integrantes da Realidade (SEVERIANO, 2013), pois também legitimava a revista para 0 governo, permitindo sua circulação sem maiores problemas, em tempos de crescente tolhimento de liberdades, sobretudo para a imprensa.

Neste artigo, será realizada uma análise crítica da narrativa (MOTTA, 2013) do primeiro perfil de um líder da Ditadura publicado pela Realidade: "Feliz Aniversário Seu Artur", presente na edição
2, de maio de 1966. A reportagem retrata Artur da Costa e Silva, quando ainda era ministro da Guerra, mas já previa que seria o próximo a ocupar o cargo máximo, de presidente. A proposta de Motta (2013) é multidisciplinar e busca compreender como se articulam os sentidos produzidos pelas narrativas, vista como uma versão entre tantas possiveis. O processo de análise vai além do texto em si, com relevância aos aspectos extralinguísticos, como o contexto e as múltiplas vozes presentes na construção da narrativa (como o jornalista, o veículo, o entrevistado) e suas intencionalidades. Apesar da perspectiva ser menos linguística e mais voltada ao aspecto cultural, também leva em consideração a estrutura do texto, elementos como as sequências, os personagens, o conflito, as expressões utilizadas, a fim de desvelar os jogos de poder presentes. Pretende-se, aqui, mostrar como a narrativa, uma forma simbólica, pode estabelecer ou sustentar relações de dominação e demonstrar os modos de operação da ideologia (THOMPSON, 2011) no texto. Ou seja, todas as escolhas feitas pelo narrador ao construir o personagem, em que também tem peso o veículo e a posição de poder do próprio perfilado (MOTTA, 2013), são capazes de edificar ou destruir personalidades perante o público. Soma-se a isso a relevância da Realidade na época, sendo a maior revista do Brasil em circulação em seus primeiros anos de existência, recorte temporal em que está o perfil analisado, chegando a uma tiragem recorde de mais de meio milhão de exemplares na edição 11 de fevereiro de 1967. Antes da análise em si, será, brevemente, discutida a possibilidade de utilização da imprensa, sobretudo das revistas, não só como fonte, mas também como objeto de pesquisa histórica.

\footnotetext{
2 Costuma-se dividir a história da Realidade em três fases: a primeira fase (1966-1968) é o período mais fértil, em que mais se concentram os estudos a respeito da publicação. Na segunda fase (1969-1973), ocorreu uma mudança na equipe e, com a edição do Ato Institucional Número 5, as dificuldades aumentaram; buscou-se manter a qualidade, apostando em edições temáticas, mas sem o mesmo sucesso. Na terceira fase (1973-1976), a revista foi descaracterizada, tornando-se uma publicação bastante diferente da concepção original, com menos aprofundamento e temáticas menos críticas

3 Edições 5, de agosto de 1966; e 10, de janeiro de 1967, respectivamente.

4 Em ambos os casos, a censura partiu do Juizado de Menores. O editorial da edição 06, de setembro de 1966, relatou a ameaça de apreensão da revista, caso prosseguisse com a pesquisa sobre juventude e sexo, a advertência dizia que o conteúdo era "obsceno e chocante". Já no caso da edição especial sobre as mulheres, a revista foi apreendida e o editorial da edição 11, de fevereiro de 1967, mostra que a apreensão se deu pelo fato da edição ser considerada "obscena e ofensiva à dignidade da mulher".
} 


\section{As revistas e a pesquisa histórica}

As mídias impressas, como jornais e revistas, constituem valorosos materiais para a prática da pesquisa histórica. São fontes capazes de expressar pensamentos e representações sociais em imagens e textos. "Em cada página nos deparamos com aspectos significativos da vida de nossos antecessores, que permitem recuperar suas lutas, ideias, compromissos e interesses" (CAPELATO, 1988, p. 13). Martins (2003) aborda o trabalho do historiador especificamente com revistas e mostra que elas constituem um

[...] conjunto lúdico que numa só publicação reúne texto, imagem, técnica, visões de mundo e imaginários coletivos. Todos os seus componentes, aparentemente corriqueiros - formato, papel, letra, ilustração, tiragem - sugerem indagações que prenunciam a carga de historicidade presente nas, hoje, velhas e amarelecidas publicações. Tem-se ali registro múltiplo, do textual ao iconográfico, do extratexto - reclame ou propaganda - à segmentação, do perfil de seus proprietários àquele dos consumidores (MARTINS, 2003, p. 60).

Além de uma fonte de acesso ao passado, com múltiplas abordagens possiveis sob diferentes ângulos e os mais diversos elementos presentes e passiveis de questionamentos, as revistas também podem ser utilizadas como um objeto em si, dignas de uma análise própria, capazes de desvelar ideologias e relações de poder na construção de narrativas, possibilitando mais um componente na compreensão da sociedade. Entretanto, como toda fonte histórica, deve passar por uma rigorosa crítica, evitando um olhar deslumbrado e inocente. As interpretações a respeito do que se apresenta em suas páginas devem ir além do visivel e buscar o não-visivel, as intenções e produções de sentido que dialogam com o contexto de produção dos materiais. Como mostra Capelato (1988):

A imprensa constitui um instrumento de manipulação de interesses e intervenção na vida social. Partindo desse pressuposto, o historiador procura estudá-lo como agente da história e captar o movimento vivo das ideias e personagens que circulam pelas páginas dos jornais. A categoria abstrata imprensa se desmitifica quando se faz emergir a figura de seus produtores como sujeitos dotados de consciência determinada na prática social (CAPELATO, 1988, p. 21).
Assim, os estudos envolvendo imprensa e história demandam certos cuidados prévios, para sair de um nivel mais abstrato e chegar a elementos mais concretos e passiveis de interpretação. Inicialmente, é preciso considerar os aspectos de produção jornalística e como se constituiu a formação do objeto de estudo, neste caso a revista Realidade. Para Capelato (1988), antes de iniciar a pesquisa, são necessárias algumas indagações para a fonte, como: "quem são seus proprietários? A quem se dirige? Com que objetivos e quais os recursos utilizados na batalha pela conquista dos corações e mentes?" (CAPELATO, 1988, p. 14). Além disso, é importante dialogar com o aspecto contextual mais amplo, a fim de compreender em que momento a publicação se insere na história da imprensa brasileira. Por isso, é necessário considerar alguns elementos prévios antes da análise: que a revista, no momento da publicação do perfil ainda gozava de certa liberdade; que a autocensura existia e não era aconselhável publicar críticas explicitas a um governo notoriamente autoritário (MARÃO; RIBEIRO, 2010); que, para a editora Abril, mercadologicamente, não era interessante se indispor com o governo; que o repórter designado para os perfis dos lideres da Ditadura circulava com aceitação entre a direita (SEVERIANO, 2013); que a redação da Realidade possuía um núcleo majoritariamente de esquerda e afrontador (SEVERIANO, 2013), ousando principalmente no plano dos costumes, sendo bastante interessante para a sobrevivência da revista a publicação de matérias bajuladoras a respeito dos ditadores (SEVERIANO, 2013); que, explicitamente, Realidade nunca afrontou o governo e nem sofreu censura política, ambos os casos que aconteceram foram ações isoladas do Juizado de Menores, ou seja, a relação não era conturbada e as estratégias de aproximação tiveram êxito; que com o Ato Institucional $N^{\circ} 5$ e a saída de vários membros da equipe, a publicação passou por significativas mudanças, representando uma nova fase (LEISTER FILHO, 2003; MARÃO; RIBEIRO, 2010), que não abarca o periodo estudado neste artigo.

O historiador Cláudio de Sá Machado Júnior também trabalha com revistas em suas pesquisas, enfocando suas análises nas fotografias 
presentes em suas páginas. De acordo com o autor, "objetos visuais e verbais não podem ser considerados elementos isolados" (MACHADO JÚNIOR, 2009, p. 42). Fotos e textos são elementos que se complementam em um periódico, por isso a análise deve dar conta dessa associação. E, ainda assim, não constituem um corpus suficiente em si para a análise, necessitando que se agreguem uma variedade maior de elementos, como, mais uma vez, as questões contextuais, fundamentais para a pesquisa.

Para que se possam elucidar os estudos sobre a sociedade, principalmente do ponto de vista histórico, é necessário que as fotografias estejam situadas em determinados contextos, cabendo ao historiador das imagens a reconstituição dos aspectos contextuais da época, buscando indicios em fontes que se complementem e que se apresentem como algo além do objeto fotográfico. Mais do que a variação de fontes trata-se da incorporação de estudos interdisciplinares (MACHADO JÚNIOR, 2009, p. 40).

Dessa forma, aliam-se análises contextuais e textuais dos perfis e a iconografia presente nas páginas da Realidade. As fotografias, bem como os textos, representam escolhas produtoras de sentido, propositalmente dispostas da forma como estão e que fazem parte de um todo indissociável, componentes da memória dos generais ditadores produzida pela revista durante a vigência da Ditadura Civil-Militar no Brasil.

\section{Artur da Costa e Silva e o autoritarismo amável}

Diferente de Humberto de Alencar Castelo Branco, perfilado uma única vez por Mercadante, ${ }^{5}$ a figura de Artur da Costa e Silva apareceu como centro de três perfis da Realidade entre os anos de $1966 \mathrm{e}$ 1967. Além de um perfil dedicado a lolanda Barbosa da Costa e Silva, ${ }^{6}$ esposa do ditador. Certamente, a figura de Costa e Silva e a sua ascensão suscitou maior atenção editorial e aumentou a preocupação com as relações entre a revista e o governo.

Antes mesmo de Costa e Silva estar no cargo de Presidente - e antes mesmo de Castelo Branco ter sido perfilado -, Realidade publicou "Feliz Aniversário Seu Artur", logo na sua segunda edição, de maio de 1966. Na época, o militar ocupava o posto de ministro da Guerra. Ele estava no cargo desde 4 de abril de 1964, logo no início da Ditadura.7

A primeira narrativa a respeito de Costa e Silva opera de modo a legitimar sua figura para o público leitor da Realidade, pois mesmo não ocupando o cargo de presidente da República, a essa altura, maio de 1966, a reportagem deixa claro que ele deverá ser o sucessor de Humberto de Alencar Castelo Branco, sendo escolhido nas eleições indiretas. Desde a primeira edição, o então ministro da Guerra já figura nas páginas da revista, pois foi um dos leitores do número "zero", que enviaram votos de sucesso à publicação e que tiveram suas cartas publicadas na edição 1.

No perfil "Feliz Aniversário Seu Artur" (MERCADANTE, 1966a), uma foto de página dupla abre a matéria com uma coluna de texto cortando a imagem (Figura 1). Costa e Silva aparece em pé, com uma longa fila a sua frente, com vários homens aguardando a vez de cumprimentá-lo. A escolha da imagem é uma referência ao jogo de linguagem feito durante a narrativa. Costa e Silva está recebendo felicitações, produzindo um efeito de figura respeitada e proeminente devido a longa fila que se forma para chegar até ele. As felicitações apontam, pelo título, para o aniversário do futuro líder do governo ditatorial, mas Mercadante costura o texto de forma a mostrar que os cumprimentos também se relacionam à posição que ele deverá ocupar em breve, como mostram a linha de apoio e o título em conjunto: "O general Costa e Silva faz anos daqui a 5 meses. Mas já existem fortes motivos para que

\footnotetext{
5 Castelo Branco foi perfilado na edição 3, de junho de 1966, em "Êste é o Humberto". Ver mais no artigo "'Êste é o Humberto' - Estratégias de construção simbólica da revista Realidade no perfil do primeiro líder da ditadura civil-militar" (FILHO, 2020).

6 Além do perfil analisado neste artigo, o personagem Costa e Silva foi construído e reconstruido por Realidade nas seguintes ocasiões: "Um garôto chamado Artur", edição 11, de fevereiro de 1967: "Há um novo tempero no poder", edição 15, de junho de 1967; e, de forma indireta, em "Dona Yolanda, a presidenta", edição 13, de abril de 1967.

7 Costa e Silva também compôs o "Comando Supremo da Revolução", junto ao almirante Augusto Rademaker e ao brigadeiro Francisco Correia de Mello, durante o governo provisório do presidente da Câmara, Ranieri Mazzili. Foram responsáveis pela edição do primeiro Ato Institucional, que determinou as eleições indiretas para presidente e vice e deu novas atribuições ao Chefe do Executivo, como o direito de cassar mandatos e suspender direitos políticos.
} 
os seus amigos the desejem FELIZ ANIVERÁRIO SEU ARTUR" (MERCADANTE, 1966a, p. 25). Isso evidencia que as intenções do texto vão muito além da comemoração do aniversário de Costa e Silva, fazendo uma relação entre a data come- morativa, que só acontecerá cinco meses depois da publicação ser veiculada, e outro fato digno de felicitações: a chegada à presidência do Brasil, pois as eleições estão previstas para o mesmo dia em que completa 64 anos, 3 de outubro de 1966.

Figura 1 - Feliz Aniversário Seu Artur

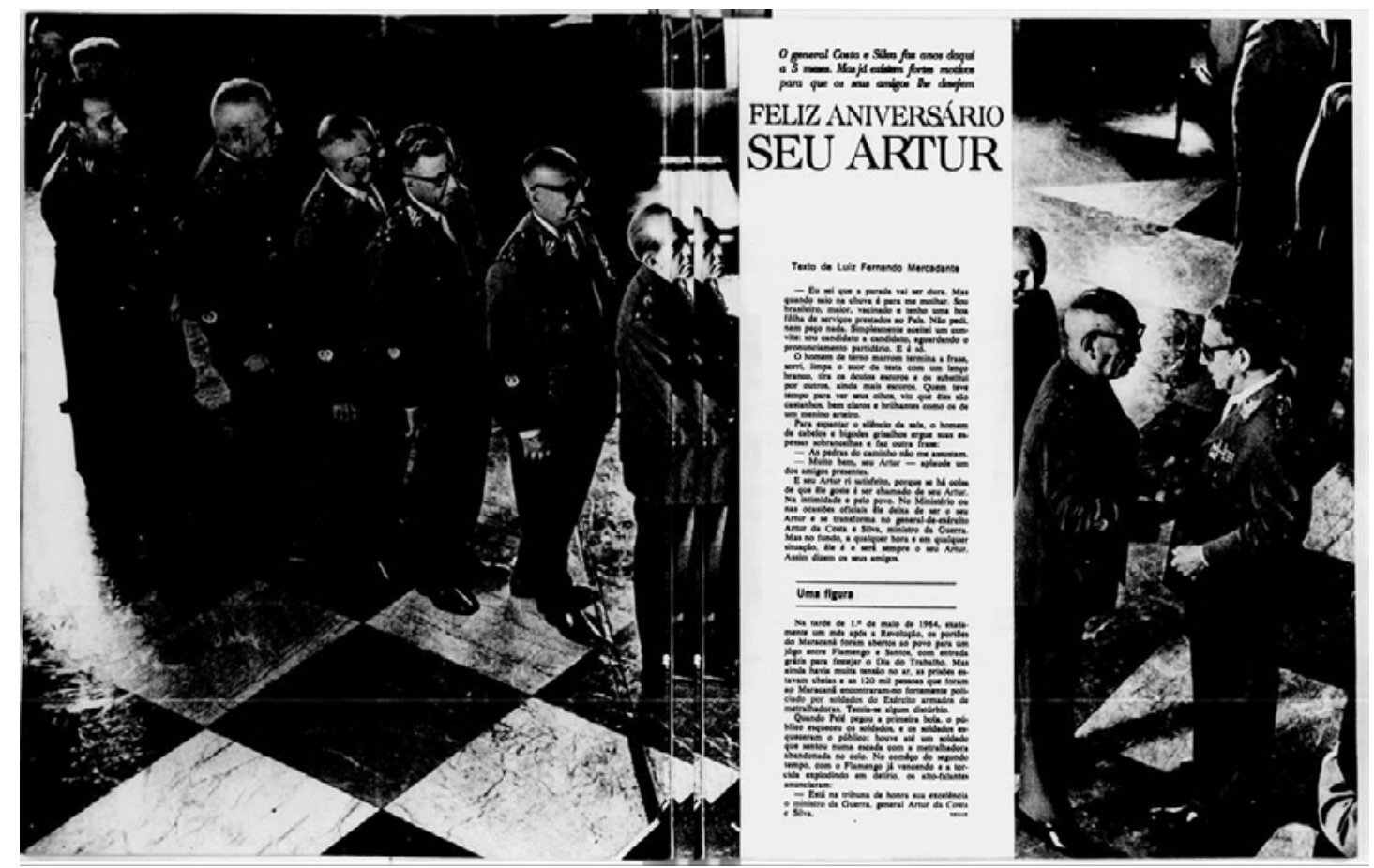

Fonte: MERCADANTE, Luiz Fernando. Feliz Aniversário Seu Artur. Realidade, São Paulo: Ed. Abril, ano I, n. 2, p. 24-29, maio de 1966.

Mercadante (1966a) abre o texto com uma fala do próprio Costa e Silva a respeito da sucessão presidencial e da sua candidatura para o pleito previsto para cinco meses após a data de publicação do perfil.

_- Eu sei que a parada vai ser dura. Mas quando saio na chuva é para me molhar. Sou brasileiro, maior, vacinado e tenho uma boa fôlha de serviços prestados ao País. Não pedi, nem peço nada. Simplesmente aceitei um convite: sou candidato a candidato, aguardando o pronunciamento partidário. E é só (MERCADANTE, 1966a, p. 25).

Apesar de Costa e Silva se apresentar apenas como "candidato a candidato", Realidade preocupa-se em pautar desde já a figura do próximo militar a ocupar o posto máximo da Ditadura. 0 teor da narrativa aponta para uma óbvia vitória de Costa e Silva nas eleições indiretas, basicamente como uma apresentação do próximo presidente do Brasil aos leitores, ao mesmo tempo em que estreita relações com o futuro ditador e com o governo. É provável que a figura de Costa e Silva desde esse momento gerasse preocupação na redação da revista, pois, mesmo antes do $\mathrm{Al}-5$, é perfilado direta ou indiretamente mais três vezes, ou seja, a publicação busca uma proximidade com o militar caracterizado no próprio texto como "durão" e autoritário. Se a autocensura (MARÃO; RIBEIRO, 2010) pairava nas redações de grandes veículos do Brasil desde o Golpe de 1964, é evidente que o porvir se mostrava ainda mais preocupante, exigindo uma dose maior de cautela. E, para isso, algumas bajulações personalistas nas páginas da Realidade poderiam ser convenientes, começando a partir da segunda edição, pois eram vistas como estratégia para a produção de matérias que a equipe realmente julgava importante e que poderiam trazer algum incômodo, colocadas entre os perfis dos militares (SEVERIANO, 2013). 
A sequência introdutória do perfil ainda apresenta uma marca registrada do futuro ditador: "tira os óculos escuros e os substitui por outros, ainda mais escuros" (MERCADANTE, 1966a, p. 25). E compara o olhar de Costa e Silva ao de um "menino arteiro", característica comum nos textos de Mercadante: referenciar a infância na construção das personagens, ${ }^{8}$ Também traço característico, semelhante ao perfil de Castelo Branco que seria publicado na edição seguinte, é a presença de elementos que aproximam a figura perfilada ao leitor, ou seja, afastam a "oficialidade", a distância de uma alta posição ocupada, como a de ministro da Guerra, tornando os militares mais "civis", apesar de sempre ressaltar a dualidade presente entre a figura "humana" e a "autoridade", utilizada quando necessária.

[...] se há coisa de que êle goste é ser chamado de Seu Artur. Na intimidade e pelo povo. No Ministério ou nas ocasiões oficiais êle deixa de ser o Seu Artur e se transforma no general-de-exército Artur da Costa e Silva, ministro da Guerra. Mas no fundo, a qualquer hora e em qualquer situação, êle é e será sempre o Seu Artur. Assim dizem os seus amigos (MERCADANTE, 1966a, p. 25).

O personagem se apresenta hábil para transitar entre ambientes que exigem diferentes posturas, apesar de sempre preferir que prevaleça a figura "humana", do Seu Artur, sujeito simples, produzindo um efeito de proximidade. No episódio seguinte, Mercadante narra uma cena de um jogo de futebol entre Flamengo e Santos, em 1964, um mês após o Golpe. No segundo tempo, os alto-falantes anunciaram: "Está na tribuna de honra sua excelência o ministro da Guerra, general Artur da Costa e Silva" (MERCADANTE, 1966a, p. 25). A torcida ficou em silêncio. A cena indica um ponto de virada na construção do personagem, pois Mercadante afirma que, se a mesma cena se passasse dois anos depois, na data de publicação do perfil, a reação seria completamente diferente: "haveria palmas, algumas vaias, mas não faltaria calor. Seu Artur já é uma figura" (MERCADANTE, 1966a, p. 26). Ou seja, o então ministro da Guerra já era uma pessoa popular e, apesar de não ser unanimidade, atingiu o patamar de "figura", conhecido pela população, pronto para se tornar o próximo presidente.

Entretanto, mesmo já sendo uma "figura", o texto tem o objetivo de apresentar Costa e Silva aos leitores. A fotografia escolhida na sequência, também ocupando página dupla, é como uma imagem de boas-vindas: a figura acolhe os leitores de braços abertos, sem os óculos escuros, discursando com a cara limpa e exposta.

Figura 2 - Feliz aniversário Seu Artur - Seu Artur tem cara de mau, é gaúcho dos bons, gosta de cavalos e sabe chorar

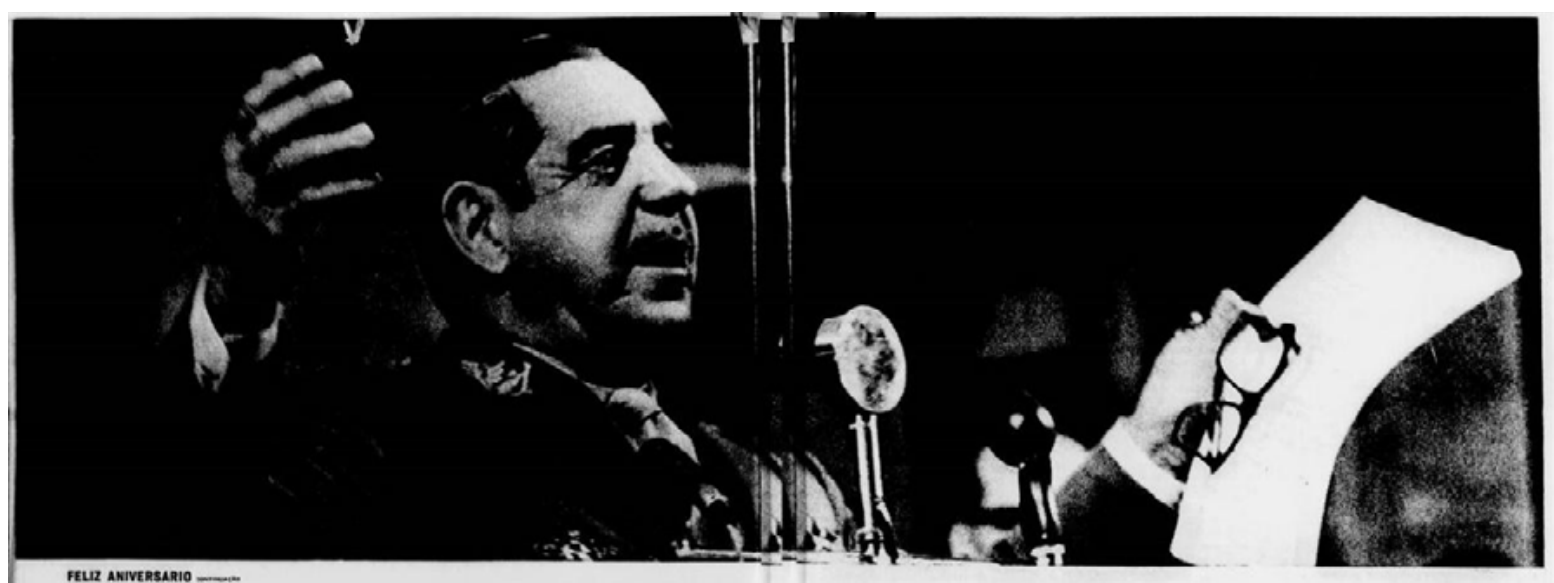

Seu Artur tem cara de mau, é gaúcho d dos bons, gosta de cavalos e sabe chorar

Fonte: MERCADANTE, Luiz Fernando. Feliz Aniversário Seu Artur. Realidade, São Paulo: Ed. Abril, ano I, n. 2, p. 24-29, maio de 1966. 
As sequências seguintes abordarão cada uma das caracteristicas elencadas abaixo da fotografia: "Seu Artur tem cara de mau, é gaúcho dos bons, gosta de cavalos e sabe chorar" (Figura 2). A sequência intitulada como "A cara feia" (MERCADANTE, 1966a, p.26) afasta possiveis preconceitos com a imagem prévia que o público pode ter do seu personagem:

Seu Artur não tem cara de muitos amigos. Quando não está falando ou sorrindo, seu ar fechadão e seu rosto vincado de rugas, combinados com os seus infaliveis óculos escuros - habituais por receita médica - lhe dão uma aparência enganadora. Mas sua simpatia natural, sem um pingo de afetação, vem no primeiro contato. É só lhe dizer bom dia e êle responderá com um bom dia gordo, de quem deseja realmente um bom dia. De longe, porém, êle tem cara de mau (MERCADANTE, 1966a, p. 26).

Isto é, basta conhecê-lo para eliminar qualquer preconceito em relação a sua cara fechada e pouco amigável. No texto, o personagem é alertado sobre a necessidade de sorrir mais para agradar ao público. O fato antecede uma comparação entre Costa e Silva e Castelo Branco, mostrando um antagonismo necessário. "- São ossos do ofício, Nélson. Eu tenho que bancar o urso e o Castelo é o bonzinho" (MERCADANTE, 1966a, p. 26). Mercadante encerra a sequência com adjetivos como emotivo e sensivel para descrever Costa e Silva, destacando a figura do avô que brinca com os netos e exaltando características comuns como se fossem excepcionais, como o fato de se preocupar com a saúde dos empregados, agregando valores "positivos" ao personagem.

Os que o cercam, entretanto, sabem que de urso não tem nada êsse homem emotivo e sensivel, capaz de passar horas brincando com os netos, de chorar diante do muro de Berlim como aconteceu em sua recente viagem ao exterior, de se preocupar com a saúde dos empregados de sua casa e de cantar, a todo pulmão, o Parabéns a Você numa festinha de aniversário (MERCADANTE, 1966a, p. 26).

Depois, Mercadante (1966a, p. 26) destaca Costa e Silva como "Um gauchão". Cita sua cidade natal, Taquari, além de apresentar características que o legitimam como um autêntico gaúcho: não recusa chimarrão, apesar de não ter o hábito de tomá-lo; conserva o sotaque do Sul; e tem amor por cavalos. O narrador utiliza o gancho para introduzir outra personagem, Dona lolanda, esposa do militar. A mulher é descrita como: "10 anos mais nova do que o marido, dona de casa dedicada e eficiente a quem seu Artur entrega seus envelopes de pagamento desde quando se casou, tenente, até hoje que é ministro" (MERCADANTE, 1966a, p. 26). Todas essas afirmações que procuram construir um lar sólido e bem estruturado nos moldes tradicionais podem ser consideradas ideológicas, pois sustentam valores pré-estabelecidos, mesmo que de forma muito sutil. A figura construida da mulher ideal, portanto, operando de modo a sustentar valores enraizados nos padrões morais da sociedade, é: mais jovem que o marido e dona de casa - vale ressaltar o "eficiente" como complemento. Além disso, pode ser responsável por cuidar do dinheiro trazido pelo marido, provedor, através do trabalho.

A afirmação seguinte dissimula9 (THOMPSON, 2011) a realidade por meio da narrativa: "Ao contrário do que muita gente pensa, seu Artur não é rico" (MERCADANTE, 1966a, p. 27). Provavelmente, o sentido de uma assertiva como essa seja aproximar o leitor médio da figura que será presidente do Brasil, criar empatia, identificação. O fato se torna bastante irônico ao seguir a leitura do parágrafo:

Tem um modesto apartamento de 5 peças no Jardim Botânico, Rio, e um outro, que ainda está pagando, em São Paulo. E nada mais, a não ser uma casa que herdou no Rio Grande do Sul. O palacete em que vive com a espôsa, o filho tenente-coronel, a nora e os quatro netos - ao lado do Maracanã - e a casa que usa em Petrópolis pertencem ao Ministério da Guerra. $O$ Aero-Willys particular que serve sua familia foi comprado a prazo (MERCADANTE, 1966a, p. 26).

Ou seja, neste trecho, após citar que o militar possui dois imóveis, o autor adiciona "e nada mais", com fins puramente retóricos, pois, após o "nada mais", ainda acrescenta outra casa, no Rio Grande do Sul, e um carro aos bens de Costa e Silva. Percebe-se uma espécie de ânsia por

9 Neste modo de operação da ideologia, as relações de dominação são apresentadas de uma forma que desvia a atenção ou passa por cima de relações e processos existentes (THOMPSON, 2011). 
humildade nas intenções do texto ao construir o personagem, o que dificilmente se sustenta com a exposição dos fatos. Mercadante pode ter sido irônico e utilizado a passagem para uma certa crítica, entretanto, pelo tom da narrativa e a forma com que o parágrafo se desencadeia, provavelmente não tenha sido esse o viés da sequência.

Em seguida, o perfil apresenta o gosto de Costa e Silva pelas corridas de cavalo e suas formas de apostar. Essa sequência encerra após o militar vencer uma das apostas e dizer: "- A vitória só bafeja a quem acredita nos nacionais" (MERCADANTE, 1966a, p. 27). Essa frase também pode ser interpretada como um traço nacionalista inserido ao perfilado, ao creditar a vitória na aposta à crença nos "nacionais", pois pode ser remanejada a outros aspectos da vida, com o sentido de que acreditar na Nação é o caminho para a vitória.

Depois, Mercadante constrói um episódio em que Costa e Silva oferece um jantar e um baile no Ministério da Guerra em comemoração ao Dia do Soldado, diferente dos anos anteriores em que aconteciam desfiles e, no máximo, banquetes pelo país. A cena, que também traz um pouco de humor ao texto, encerra, já em outro evento, com uma conversa entre a atriz sueca Gunner Lindblom e Costa e Silva:

- O senhor não é ministro da Guerra. O senhor é o ministro da Paz. Seu Artur sorriu, satisfeito. Logo adiante virou-se para um acompanhante, apontou para uma bonita mulher que estava de costas e perguntou:

- Quem é aquela fidalga? (MERCADANTE, 1966a, p. 27).

Mercadante atribui, pela narrativa, mais sentidos "positivos" à figura de Costa e Silva ao chamá-lo, pela voz de uma atriz internacional, de ministro da Paz, além de encerrar a cena com um toque de informalidade à figura poderosa do militar.

Em "O bom de Papo" (MERCADANTE, 1966a, p. 27), o perfil aborda a relação de Costa e Silva com a imprensa. Antes, com declarações fortes e, agora, candidato à Presidência, está "caladão". Mercadante sugere um possivel pacto com Castelo Branco, para não por "lenha na fogueira" (MERCADANTE, 1966a, p. 27). O episódio ainda traz algumas declarações do então candidato em situações como entrevistas coletivas realizadas em suas viagens para o exterior ou no Brasil mesmo, mas as respostas são sempre em tom evasivo ou até bem humorado.

A sequência seguinte, "Um capote" (MERCADANTE, 1966a, p. 28), reitera seguidas vezes a relação de amizade entre Costa e Silva e Castelo Branco. ${ }^{10} \mathrm{O}$ capote, um sobretudo que Seu Artur tratava com muito cuidado nas viagens para o Oriente Médio e para a Europa, foi emprestado por Castelo Branco. Talvez para afastar qualquer desconfiança sobre a relação entre os dois militares, até mesmo pela questão da sucessão presidencial, o texto se torna forçado e repetitivo, reforçando o laço em cada afirmação, o que indica uma transição de governo pacífica e amigável. A própria figura do capote ganha um significado de zelo, de carinho, um objeto que carrega em si a representação de uma forte ligação, pois Costa e Silva não o perde de vista durante toda a viagem e o escova todos os dias. "Quem lhe emprestou, para enfrentar o inverno europeu, foi um seu amigo, de muitos anos, de mais de 50 anos, o marechal Humberto de Alencar Castelo Branco" (MERCADANTE, 1966a, p. 28). O texto mostra que a amizade vem desde quando eram meninos no Colégio Militar de Porto Alegre.

Dêsse tempo, seu Artur guarda com carinho em sua estante um livro com dedicatória afetuosa: "Ao mais distinto aluno da nossa turma, oferece o Cearense". Êsse cearense da dedicatória é o próprio Castelo Branco, o mesmo que emprestou o capote que serviu para esquentar seu Artur na Europa (MERCADANTE, 1966a, p. 28).

A sequência encerra afirmando que a velha amizade entre os dois militares tem resistido às

10 É curioso notar como a construção do personagem Costa e Silva se dá ao longo do tempo na Realidade, sofrendo algumas mutações de características, como no caso da relação com Castelo Branco. Se, aqui, são amigos próximos e o afeto é marcado pelo simbolismo do capote, mostrando uma transição leve e amigável, nos perfis seguintes os sentidos serão diferentes. Já no cargo de Presidente, Costa e Silva será distanciado do seu antecessor. Em "Um garôto chamado Artur", Mercadante (1967a) focalizará certa rivalidade com Castelo Branco, durante o periodo de Escola Militar, com vantagem sempre para Costa e Silva. E, depois, em "Há um novo tempero no poder" (MERCADANTE, 1967c), é justamente na diferenciação de seus predecessores que se constrói a imagem de Costa e Silva, nesse caso, posto em perspectiva, sempre vantajosa, com Castelo Branco, João Goulart, Jânio Quadros e Juscelino Kubitscheck. 
intrigas e ao jogo da política, com Costa e Silva caracterizando-a como "indestrutivel". Em "As crianças", Mercadante (1966a, p. 28) utiliza os netos para amaciar a personalidade de Costa e Silva. A sequência funciona quase como uma introdução para o episódio seguinte, "Um durão" (MERCADANTE, 1966a, p. 28), mostrando que existe ternura e leveza dentro do personagem, sempre com características bastante comuns a um avô, mas que, dentro desse contexto narrativo, tornam-se excepcionais, afinal dão um toque de humanismo ao personagem que, provavelmente, antes da publicação era idealizado pelo leitor como fechado, sério, autoritário. Entre esses traços afetuosos estão: preocupar-se com o neto que está no hospital para operar de uma apendicite; sair com os quatro netos, "vão sempre comprar sorvetes ou doces. Os 4 netos e o avô que, apesar do regime, não resiste a sorvete nem a doce" (MERCADANTE, 1966a, p. 28); brincam no quintal; já foi surpreendido por um empregado atrás de uma árvore brincando de esconde-esconde; conta histórias, quase sempre de soldados e de heroísmo pela pátria. A construção do avô afetuoso também será utilizada na narrativa de Mercadante sobre Castelo Branco (MERCADANTE, 1966b) e certamente é uma ótima forma de atribuir sentido "positivo" aos personagens, sensiveis no âmbito familiar, mas que, na hora de cumprir sua missão pelo Brasil, as narrativas apontam que ambos sabem enrijecer e são capazes de assumir a responsabilidade com seriedade.

E é exatamente para essa dualidade que o texto recorre em seguida. Se, por um lado, tínhamos uma figura amável com os netos, o episódio seguinte inicia com um traço oposto na personalidade de Costa e Silva: "- Mas que êle é duro na queda, isso êle é - diz quem o conhece - e em matéria de disciplina é inflexivel. Mais de uma vez teve que punir oficiais seus amigos, gente de sua inteira confiança e a quem êle quer muito bem. Não hesitou. Puniu mesmo. Até com prisão" (MERCADANTE, 1966a, p. 28). Agora, o personagem aparece como uma referência de moralidade. O fato de "punir gente de sua inteira confiança" mostra que seu compromisso com a disciplina, com o cargo, com a pátria, está acima das relações particulares. Mercadante constrói uma imagem séria e incorruptivel, reforçada com a passagem seguinte: "Além de duro, o general é rude quando quer. Se alguém the pede ou sugere alguma coisa menos honesta, seu Artur bota a bôca no mundo. Uma vez deu uma corrida num grupo de industriais que queriam usar seu prestígio para negócios particulares" (MERCADANTE, 1966a, p. 28). Qualquer possibilidade de corrupção é afastada da imagem de Costa e Silva, um sentido valoroso para uma construção de uma figura que, agora, torna-se politica e almeja a presidência da República nos próximos meses, pois transmite uma sensação de confiança ao leitor. Ainda em "Um durão", Mercadante (1966a, p. 28) conta uma história sobre como Costa e Silva, certa feita, acabou com uma rebelião dos bombeiros apenas ordenando que as tropas rebeladas voltassem ao quartel, afirmando que aquilo era indisciplina. Essa sequência atribui um forte traço de autoridade e respeito ao personagem.

Mas essa não deve ser a imagem definidora do personagem prestes a se tornar presidente. Se Mercadante fez questão de atenuar o tom do relato antes de apresentá-lo como "durão", faz isso de maneira ainda mais caricata após o episódio. Ele afirma que Costa e Silva só usa a mão esquerda quando está bravo, ou quando "a coisa fica preta" (MERCADANTE, 1966a, p. 28), um exemplo é quando acompanha os jogos do Flamengo e utiliza a canhota para dar soquinhos na palma da mão direita (MERCADANTE, 1966a, p. 28). O personagem ganha o traço de flamenguista doente, outra caracteristica geradora de identificação, e o narrador encerra a sequência incorporando uma doçura quase encantadora ao perfilado:

Mas êsse homem franco, rude e autoritário,
tem o seu lado ameno: gosta de dançar com
a espôsa e, às vezes, põe um disco na vitrola
e dá uns volteios com dona lolanda pela sala;
aprecia boas anedotas e as conta com muita
graça; levanta-se sempre assobiando earrisca
um lá-lá-lá no chuveiro; é capaz de passar uma
hora entretido com o nascer ou o pôr do Sol;
acha o mar muito bonito mas se entusiasma
mesmo é diante de montanhas; antes de ser
ministro saía para longos passeios matinais
carregando uma bengalinha e balas para as
crianças que ia encontrando no caminho; e 
escreveu muita poesia quando môço. Uma delas começa assim:

- Eu sou a abelha do amor (MERCADANTE, 1966a, p. 28).

Não por acaso, a narrativa segue com um novo episódio nomeado por Mercadante (1966a, p. 28-29) como "Uma aspiração"; logo após o giro de durão para uma figura sensivel, generosa e poética do velhinho de bengala que distribui doces, o perfil passa a abordar a maior pretensão de Costa e Silva: tornar-se presidente do Brasil. O texto aborda brevemente a trajetória do militar até se tornar candidato, ressaltando o seu prestígio dentro das Forças Armadas. Em mais de uma passagem, Mercadante supõe que esta é uma eleição já ganha, pois conta com quase unanimidade entre a oficialidade e no Congresso, responsável pela eleição indireta, "já armou um esquema poderoso" (MERCADANTE, 1966a, p. 28). Mas, claro, a narrativa também precisa legitimar seu nome para a população brasileira, mostrando que já possui inserção positiva na boca do povo: "Seus partidários afirmam que na simpatia popular seu nome vem crescendo na medida em que êle representa as aspirações do povo por uma vida melhor, menos sacrificada, mais digna e mais humana" (MERCADANTE, 1966a, p. 28-29). Ao afirmar que seu prestígio vem crescendo entre o povo e que ele representa os anseios da sociedade, a narrativa pode dar peso para a figura perfilada entre leitores que mal conheciam o militar.

Depois, a narrativa se volta para a plataforma de governo sonhada por Costa e Silva. Apresentada de forma superficial e vaga, ela se baseia no binômio Paz e Produção, essenciais para o desenvolvimento, segundo "seu Artur". "E o que ele se propõe é pacificar a familia brasileira e estimular a produção de tal modo que o País acelere sua marcha para o desenvolvimento" (MERCADANTE, 1966a, p. 29). O discurso simplista nada diz, de fato, sobre como irá governar ou sobre suas estratégias para solucionar problemas do Brasil, mas, dentro da proposta do texto, não deixa de ser uma plataforma convincente e sedutora para um leitor desatento e que procura soluções simples. O texto reforça sua capacidade para gerir o
Brasil ao adicionar traços ao personagem como a preocupação em aprender com exemplos do exterior, mostrando que em sua recente viagem buscou conhecer como cada um dos sete países visitados lidava com problemas de habitação, alimentação, educação e assistência social. Como se o fato de ter visitado "silos da Alemanha", "casas populares da França e da Itália" e "escolas inglesas" legitimasse ainda mais sua capacidade de "desenvolver" o Brasil, com soluções de fora, ou melhor, da Europa, reforçadas pelos complementos (MERCADANTE, 1966a, p. 29). O final dessa sequência mostra um personagem pacificador, conciliador e comprometido com a democracia:

\begin{abstract}
Outro sonho do general é oferecer uma paz integral a tôdas as facções politicas nacionais e levar as correntes a trabalharem com êle pela prosperidade do Brasil. Êle não diz, mas seus colaboradores sabem que sua maior obra será a de encaminhar o País para uma redemocratização ampla e sem preconceitos (MERCADANTE, 1966a, p. 29).
\end{abstract}

É evidente que munidos da principal arma da História, a retrovisão, temporalmente afastada dos fatos, as palavras acima parecem irônicas e bastante incômodas, principalmente por referirem-se ao lider da Ditadura no periodo de edição do Al-5. associado na narrativa a conceitos como paz e democracia. Entretanto, escritas enquanto Costa e Silva ainda era candidato, atribuem um sentido de conforto e tranquilidade aos leitores da Realidade.

Em seguida, o perfil é dedicado ao lado "político" de Costa e Silva:

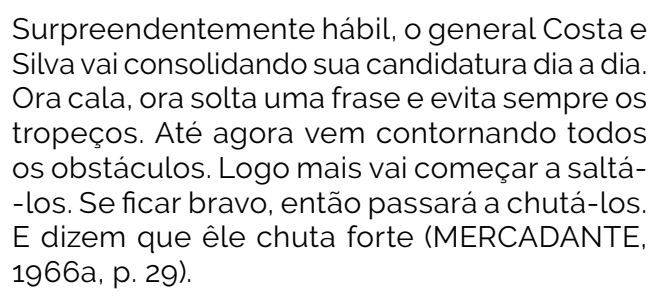

Aúltima frase também é o entretítulo em destaque na página dupla final da reportagem, "Se ficar bravo, seu Artur vai chutar os obstáculos. E chutar forte" (Figura 3). 
Figura 3 - Feliz aniversário seu Artur - Se ficar bravo, seu Artur vai chutar os obstáculos. E chutar forte

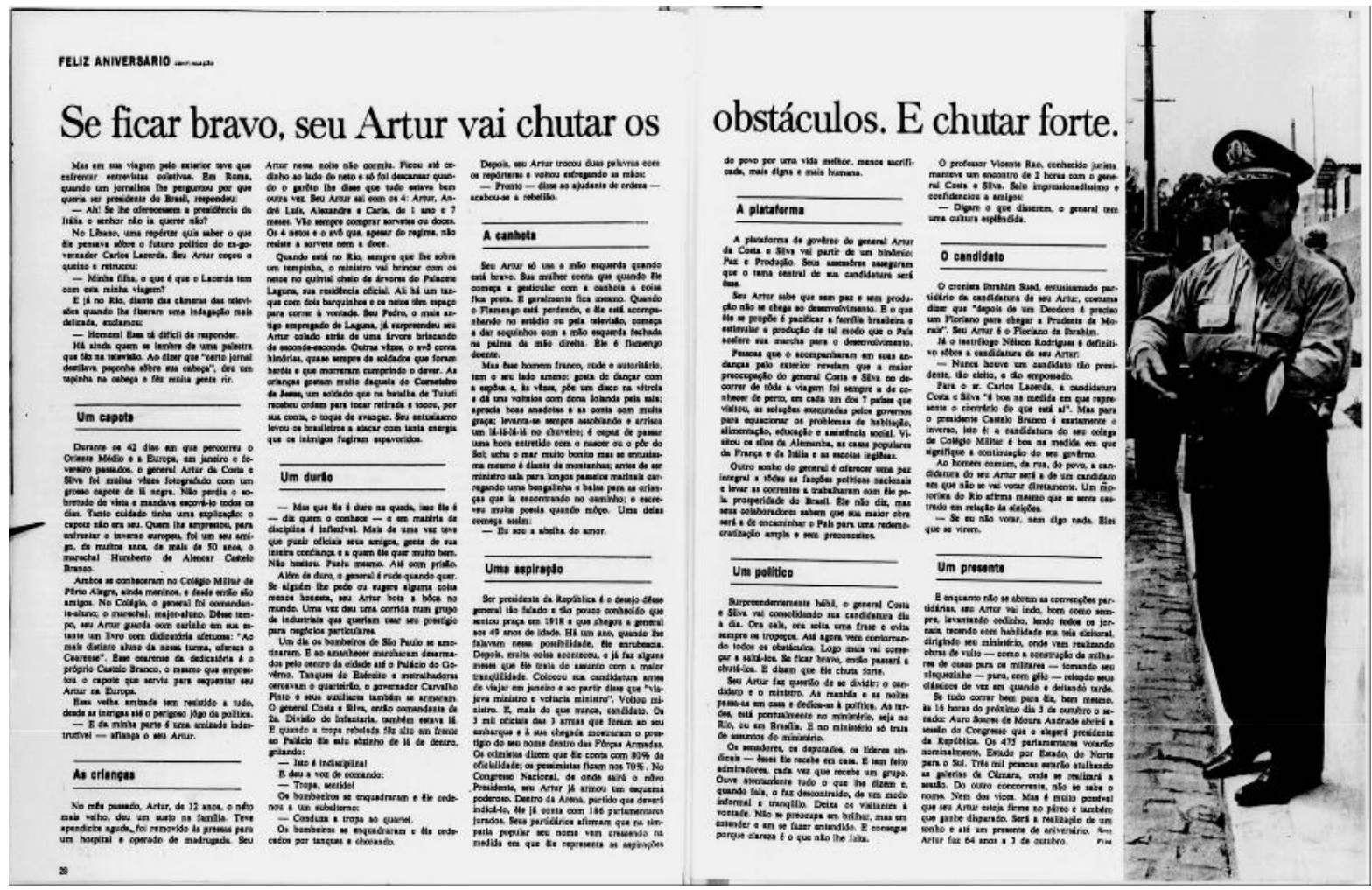

Fonte: MERCADANTE, Luiz Fernando. Feliz Aniversário Seu Artur. Realidade, São Paulo: Ed. Abril, ano I, n. 2, p. 24-29, maio de 1966 .

A frase de Mercadante podia prenunciar uma expectativa de enrijecimento do regime com a eleição do novo presidente. Chutar os obstáculos era justamente a forma de governar instaurada com o Golpe de 1964, seja por uma suposta institucionalidade, uma legalidade mascarada, como os atos institucionais, ou de forma mais repressiva, violando Direitos Humanos e promovendo o Terrorismo de Estado (PADRÓS, 2009), institucionalizado pós-Al-5. Portanto, dependendo do conceito de "obstáculo" assumido pelos leitores, é possivel que Mercadante tenha tentado precavê-los do que imaginava estar por vir, dada a fama de autoritário da figura que perfilava.

Seja uma crítica consciente ou não, fato é que o texto logo volta ao tom moderado e enaltecedor do personagem. Mostra como divide o tempo entre a política (manhã e noite) e o Ministério (tarde); como recebe em casa os deputados, os senadores e os líderes sindicais, conquistando cada vez mais admiradores, pois é um ouvinte atencioso e responde de forma descontraida, informal e tranquila. "Deixa os visitantes à vontade. Não se preocupa em brilhar, mas em entender e em se fazer entendido. E consegue porque clareza é o que não the falta" (MERCADANTE, 1966a, p. 29). A sequência ainda termina com uma fala de Vicente Rao, após um encontro de duas horas "- Digam o que disserem, o general tem uma cultura esplêndida" (MERCADANTE, 1966a, p. 29).

Em "O candidato" (MERCADANTE, 1966a, p. 29), são apresentadas diferentes opiniões a respeito de Costa e Silva. Para Ibrahim Sued: "Depois de um Deodoro é preciso um Floriano para chegar a Prudente de Morais" (MERCADANTE, 1966, p. 29). Para Nelson Rodrigues "-Nunca houve um candidato tão candidato, tão eleito, e tão empossado" (MERCADANTE, 1966a, p. 29). Carlos Lacerda espera um governo contrário ao que está posto e, por outro lado, Castelo Branco espera a continuidade do seu governo (MERCADANTE, 1966a, p. 29). Pelas citações escolhidas pelo autor (MERCADANTE, 1966a, p. 29), pode-se interpretara eleição de Costa e Silva dada como certa, inques- 
tionável; a associação da sua figura ao autoritarismo; e a crença em uma sucessão civil após o seu governo. Realidade coloca o que provavelmente seria a opinião editorial da revista na boca de um motorista qualquer, com um teor crítico, a fim de evitar qualquer conflito com o sistema instaurado:

Ao homem comum, da rua, do povo, a candidatura do seu Artur será a de um candidato em que não se vai votar diretamente. Um motorista do Rio afirma mesmo que se sente castrado em relação às eleições:

- Se eu não votar, nem digo nada. Êles que se virem (MERCADANTE, 1966, p. 29).

Essa estratégia pode ser compreendida como uma pequena forma simbólica contestatória ${ }^{11}$ (THOMPSON, 2011) em uma narrativa hegemonicamente favorável ao perfilado, mas nessas dissimulações sutis é possivel desviar a atenção do leitor e inserir a opinião antissistêmica e pró-democracia da revista. Mercadante (1966a, p. 29) cria a sequência final, "Um presente", trazendo novamente um pouco da rotina de Costa e Silva, misturando a vida política a traços da vida cotidiana.

E enquanto não se abrem as convenções partidárias, seu Artur vai indo, bom como sempre, levantando cedinho, lendo todos os jornais, tecendo com habilidade sua teia eleitoral, dirigindo seu ministério, onde vem realizando obras de vulto - como a construção de milhares de casas para os militares - tomando seu uisquezinho - puro, com gêlo - relendo seus clássicos de vez em quando e deitando tarde (MERCADANTE, 1966a, p. 29).

O narrador mostra que a rotina segue na expectativa pelo dia 3 de outubro, quando, "se tudo correr bem", será eleito presidente da República pelos 475 parlamentares que votarão no Congresso (MERCADANTE, 1966a, p. 29). Mercadante elabora um jogo retórico com a data para retomar o título e o início do texto, numa espécie de fio condutor da narrativa. "Do outro concorrente, não se sabe o nome. Nem dos vices. Mas é muito possivel que seu Artur esteja firme no páreo e também que ganhe disparado. Será a realização de um sonho e até um presente de aniversário. Seu Artur faz 64 anos a 3 de outubro" (MERCADANTE, 1966a, p. 29).

O perfil que apresenta Costa e Silva aos leitores de Realidade foi publicado em maio de 1966, no mês anterior ao perfil de Castelo Branco (MERCADANTE, 1966b), que era o lider do governo ditatorial na época. É possivel notar semelhanças na estrutura narrativa de ambos, com o estilo de Mercadante bem demarcado, recorrendo a saidas muito parecidas para construir os personagens: a afetividade com a familia; traços pessoais privados, geralmente com cenas do cotidiano; a capacidade de mesclar perfeitamente a dureza quando se trata do trabalho, com seriedade e responsabilidade, e a leveza nas relações interpessoais. Nesse caso, a ideologia pode operar por meio da unificação ${ }^{12}$ (THOMPSON, 2011), criando nos personagens uma identidade que corresponde às expectativas do brasileiro médio, leitor de revistas, utilizando a padronização (THOMPSON, 2011) como estratégia de construção simbólica em ambos os casos, pois, analisados de forma mais geral, os perfis de Castelo Branco e Costa e Silva partem de um mesmo referencial padrão como modelo de homem ideal para liderar a nação, produzindo identificação e confiança do público. Entretanto, esse primeiro perfil de Costa e Silva é sutilmente menos simpático. A relação com o autoritarismo fica evidente, até mesmo nas passagens em que Mercadante tenta afastar essa característica, pois a imagem mais dura sempre volta, seja nas descrições do narrador, na fala de outras pessoas, seja na fala do próprio perfilado. 0 fato de ser parabenizado cinco meses antes e de todos já esperarem um desfecho óbvio no pleito, e isso ser dito repetidas vezes, pode demonstrar uma crítica da publicação em relação ao regime ditatorial, à falta de democracia e uma insatisfa-

\footnotetext{
${ }_{11}$ A Forma Simbólica Contestatória pode ser uma intervenção desafiadora, transformadora (do status quo). "[...] as pessoas, ao invés de aceitar passivamente as formas ideológicas e as relações de dominação por elas sustentadas, podem contestar ou denunciar essas formas e relações, podem ridicularizá-las ou satirizá-las, podem procurar esvaziar qualquer força que as expressões ideológicas possam ter em circunstâncias particulares. Fazendo isso, essas pessoas estão engajando-se não na promulgação de uma nova ideologia (embora, sob outros aspectos, elas possam estar também fazendo isso); ao contrário, elas estão se engajando numa versão incipiente de uma forma de crítica" (THOMPSON, 2011, p. 91).

12 Relações de dominação estabelecidas e sustentadas por formas simbólicas que criam uma unidade que interliga individuos em uma identidade coletiva, independente das diferenças e divisões que possam separá-los (THOMPSON, 2011).
} 
ção com as eleições indiretas. A reiteração do fato ao longo de todo o texto evidencia isso, apesar de não ser uma característica dominante no perfil.

\section{Considerações finais}

Com a confirmação da chegada de Costa e Silva ao poder, Realidade utiliza a personalidade do novo ditador como pauta em outras oportunidades, todas no ano seguinte, 1967, mostrando uma necessidade maior de construir e reconstruir esse personagem por diferentes vieses, em um diálogo cada vez mais próximo e necessário com a Ditadura, por se tratar de um veículo da grande imprensa em um cenário que caminhava para o aumento da repressão e o cerceamento cada vez maior da liberdade de expressão. Na edição 11, o jornalista Luiz Fernando Mercadante vai até Taquari, cidade natal de Costa e Silva, e, em uma estrutura semelhante à Jornada do Herói, justifica sua posição de poder em uma narrativa que parte da infância do perfilado. Na edição 13. quem é perfilada é a esposa do general, lolanda Barbosa da Costa e Silva, e, na contramão dos valores pregados em outras oportunidades pela revista, o texto esboça um papel feminino extremamente conservador e, por tabela, enaltece, mais uma vez, o líder do governo ditatorial. Por fim, ele é pautado na edição 15, e o personagem é construido em oposição aos ex-presidentes Juscelino Kubitscheck, Jânio Quadros, João Goulart e Humberto de Alencar Castelo Branco, sempre com Costa e Silva representando a melhor opção.

As análises mostram que a narrativa de Mercadante sustentou o poder exercido pelos ditadores militares, ou seja, legitimou o governo para o público leitor da revista. Mais do que isso, sustentou também a ideologia dominante conservadora, algo que parece paradoxal, tendo em vista o caráter e a pretensão transgressora da publicação no plano dos costumes durante a sua primeira fase.

Por isso, este artigo procurou desvelar o grande poder contido na narrativa, por mais simples, informal, asséptica que ela pareça ser. A imprensa é um dos locais onde o poder age com a possibilidade de edificar personagens construidos narrativamente, ou seja, um dos palcos onde a memória é criada e disputada. Mas a construção do personagem pelas escolhas do narrador pode produzir múltiplos efeitos; um deles, é manter relações de dominação. O encadeamento de ideias contido nos perfis, todas as escolhas feitas em detrimento de outras, os traços presentes, os traços omitidos, tudo isso, presente na versão hegemônica, auxilia na construção da figura perfilada no imaginário do leitor, nesse caso, agregando um sentido amplamente positivo e justificando sua posição.

Isso de forma alguma quer dizer que o repórter foi injusto, mentiroso, procurou enganar o leitor ou que as informações eram falsas. Mas as escolhas das cenas, das características, dos diálogos, das descrições, dos episódios, fortaleceram a imagem dos ditadores, atribuindo sentido "positivo" aos ocupantes do poder. Por outro lado, características negativas que deturpassem suas imagens, consciente ou inconscientemente, dificilmente compunham a versão final da narrativa, uma forma simbólica ideológica, nos termos de Thompson (2011). Por fim, é importante ressaltar que esse aspecto conservador (FARO, 1999) não era um padrão dominante na primeira fase da revista Realidade, mas aparecia durante os perfis dos ditadores, como estratégia de sobrevivência da revista em meio à Ditadura.

\section{Referências}

CAPELATO, Maria Helena Rolim. A imprensa na história do Brasil. São Paulo: Contexto/EDUSP, 1988.

FARO, J.S. Revista Realidade, 1966-1968. Tempo da reportagem na imprensa brasileira. Porto Alegre: Ulbra/ AGE, 1999 .

FILHO, J. M. (2020). Êste é o Humberto - Estratégias de construção simbólica da revista Realidade no perfil do primeiro líder da ditadura civil-militar. Oficina Do Historiador, Porto Alegre v. 13, n. 1, p. 1-14, jan-jun 2020. https://doi.org/10.15448/2178-3748.2020.1.36660

LEISTER FILHO, Adalberto. Entre o sonho e a realidade: pioneirismo, ascensão e decadência da revista realidade (1966-1976). Dissertação (Mestrado em História) - Faculdade de História, Universidade de São Paulo, São Paulo, 2003

LEMOS, Renato. Artur da Costa e Silva (Verbete). Rio de Janeiro: Centro de Pesquisa e Documentação de História Contemporânea do Brasil, Fundação Getúlio Vargas. 
MACHADO JÚNIOR, Cláudio de Sá. Imagens da Sociedade Porto-Alegrense: vida pública e comportamento nas fotografias da Revista do Globo (década de 1930). São Leopoldo: Oikos, 2009.

MARÃO, José Carlos; RIBEIRO, José Hamilton. Realidade re-vista. Santos, SP: Realejo Edições, 2010.

MARTINS, Ana Luiza. Da Fantasia à História: folheando páginas revisteiras. História. v. 22, n. 1. São Paulo: UNESP, 2003. pp. 59-79. https://doi.org/10.1590/S0101.90742003000100003

MERCADANTE, Luiz Fernando. Feliz aniversário Seu Artur. Realidade. São Paulo: Ed. Abril, ano I, n. 2, maio 1966a.

MERCADANTE, Luiz Fernando. Êste é o Humberto. Realidade. São Paulo: Ed. Abril, ano I, n. 3, junho 1966b.

MERCADANTE, Luiz Fernando. Um garôto chamado Artur. Realidade. São Paulo: Ed. Abril, ano II, n. 11, fevereiro 1967 .

MERCADANTE, Luiz Fernando. Dona Yolanda, a presidenta. Realidade. São Paulo: Ed. Abril, ano II, n. 13 , abril 1967b.

MERCADANTE, Luiz Fernando. Há um nôvo tempêro no poder. Realidade. São Paulo: Ed. Abril, ano II, n. 15 , junho 1967c

MOTTA, Luiz Gonzaga. Análise Crítica da Narrativa. Brasilia: Editora Universidade de Brasilia, 2013

PADRÓS, Enrique Serra. História do Tempo Presente, Ditaduras de Segurança Nacional e Arquivos Repressivos. Florianópolis: Tempo e Argumento, v. 1, n. 1, p. 30-45, jan./jun. 2009

REALIDADE. São Paulo: Ed. Abril, ano I, n. 05, agosto 1966.

REALIDADE. São Paulo: Ed. Abril, ano I, n. 06, setembro 1966.

REALIDADE. São Paulo: Ed. Abril, ano II, n. 10, janeiro 1967.

REALIDADE. São Paulo: Ed. Abril, ano II, n. 11, fevereiro 1967.

SEVERIANO, Mylton. Realidade: história da revista que virou lenda. Florianópolis: Insular, 2013.

THOMPSON, John B. Ideologia. In: THOMPSON, John B. Ideologia. Ideologia e cultura moderna: teoria social crítica na era dos meios de comunicação de massa. Petrópolis: Vozes, 2011, p. 43-99.

\section{Jonas Migotto Filho}

Mestre em História pela Universidade Federal de Santa Maria (UFSM), Rio Grande do Sul, RS, Brasil.

\section{Endereço para correspondência}

Jonas Migotto Filho

Universidade Federal de Santa Maria (UFSM)

Av. Roraima, 1000 - Cidade Universitária

Camobi, 97105900

Prédio 26, Sala 1105

Santa Maria, RS, Brasil 